\title{
Mobility and Traffic Based Performance Evaluation of MANET Routing Protocols
}

\author{
Swati Gaur ${ }^{1}$, Anurag Kumar ${ }^{2}$ \\ ${ }^{1}$ MTech Student (CSE) GRDIMT, Dehradun, India \\ ${ }^{2}$ Assistant Professor GRDIMT, Dehradun, India
}

\begin{abstract}
Ad-hoc network is a collection of two or more nodes with wireless communication. They have ability to communicate without centralized manner. Ad-hoc network is temporary. Infrastructure less and de-centralized network. It is a self configuring network. Nodes do not sleep in ad-hoc network. Mobile ad-hoc network (MANET) is a collection of mobile nodes. There are many types of routing protocols for maintaining the devices over the network. The main objective of routing protocols is accurate and efficient route establishment between mobile nodes so that message may be delivered in time. In this thesis, we analyze two routing protocols for MANET- the destination sequenced distance vector (DSDV), table driven protocol and Ad-hoc on demand distance vector (AODV) an on -demand protocol and evaluates both protocols with increasing number of nodes, sources based on jitter, send packets, received packets, routing packets, packet delivery fraction, Normalized routing load, average end to end delay, number of dropped packets. Additionally, We evaluate both protocols with varying traffic (congestion/CBR Load) and mobility of nodes and calculate the number of send, received and routing packets.
\end{abstract}

Keywords: AODV, DSDV, MANET, Routing Protocols, NS2, Performance Parameters

\section{Introduction}

Ad-hoc wireless networks are having a capability that operates without the support of fixed infrastructure. Hence, they are also known as Infrastructure less networks. In comparison to cellular networks, routing is complex in Adhoc networks because there is no base station or central coordinator. In ad-hoc networks, the routing is performing in a distributed manner through each node.

Wireless communication between mobile users is more popular than before.

Ad-hoc network is an approach to communicate many users in one network. In Ad-hoc network, every node create certain packets that deliver from sender to receiver but transmission ranges of this type of network is smaller as compared to typical cellular system which consist of central control system or base station. But Ad-hoc network is better on comparing with cellular system.

The benefits of MANETs are:

- On demand

- Fault acceptance

- uncontrolled connectivity

There is no pre-established infrastructure in Ad-hoc network because it is on demand and since there is no central controller on it, every node has ability to create path and send information. This type of network is useful when the network life is short and we need it for short time period. For example, when people taking part in conference and can form network for short time period. In disaster recovery and communication where rapid changes of communication network is needed.

In Ad-hoc network, because of the absence of base station nodes are forwarding packets to other nodes. For this we need some routing protocols and routing algorithms for it. Every protocol has some advantages and disadvantages too and useful on some circumstances only.

\section{AD-HOC Routing Protocol}

Basically, there are four types of routing protocols named as Proactive, Reactive, Hybrid and Geographical routing protocol. Proactive routing protocol is table driven that updates its own routing table by all the nodes. Reactive routing protocols are also known as on-demand it does not maintain any routing table but gives information only when it is needed. Hybrid routing protocol is a combination of proactive and reactive routing protocol, it takes the features of both the routing protocols. Geographical routing protocol is based on the topology of network. It changes when topology of node changes.

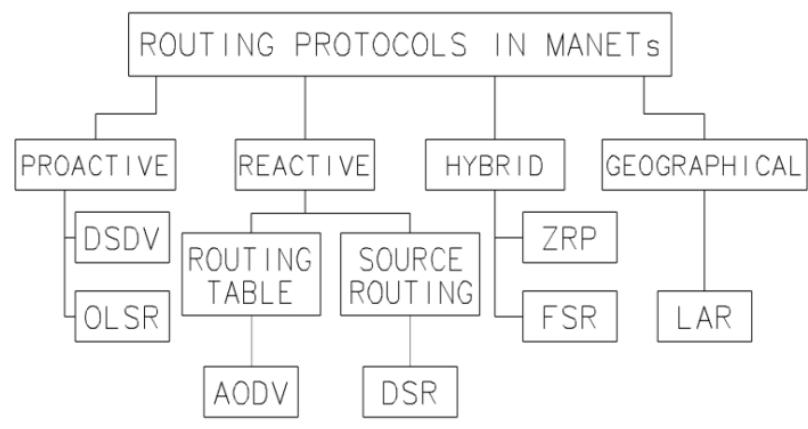

Figure 1: Classification of Ad-hoc routing protocols

2.1 Proactive protocols are also referred to as table-driven routing protocols. In these types of protocols source node make routing table for each destination node.

\subsubsection{Destination Sequenced distance vector (DSDV)}

DSDV routing protocol is based on bellman ford routing algorithm. Every cellular station maintains routing entries of all the available destination nodes. Number of hops visit to 


\section{International Journal of Science and Research (IJSR) \\ ISSN (Online): 2319-7064}

Index Copernicus Value (2015): 78.96 | Impact Factor (2015): 6.391

reach destination and sequence number is also used. When new packet arrives then sequence number is increased by one. The station periodically transfers the routing information to its neighboring node.

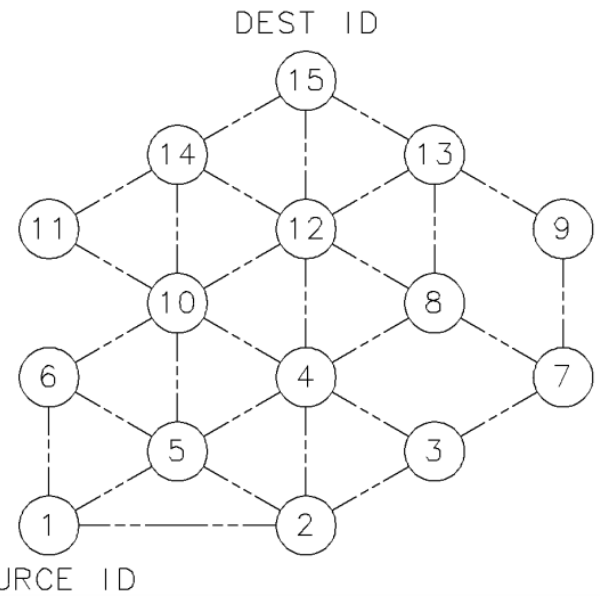

Figure 2: Route Establishment in DSDV

In figure: Node 1 is the source node and node 15 is destination. Here routes are already available. Routing table indicates that shortest route from sender to receiver is through node 5 with 4 hops.

\subsection{Reactive Routing protocols (On-demand)}

As compare to table driven, On-demand routing protocols execute path finding and exchange information regarding routing when path is required by node.

\subsubsection{Ad-hoc on demand distance vector routing protocol (AODV)}

AODV share's DSR's on demand characteristics in that it also discovers routes on an as needed basis via a correlated route discovery process. However, AODV adopts a totally different mechanism to take care of routing information. The AODV is reactive as opposed to proactive protocols like distance vector i.e. AODV only request a route once required and will not need nodes to manage routes to destination that do not seem to be active in communication.

AODV uses sequence numbers to maintain at each destination to updates routing data to all nodes. All routing packets carry these sequence number. A necessary feature of AODV is that it maintains timer based on states in every node, regarding utilization of individual routing table entries. A routing table entry is expired if not used recently.

When one node wants to communicate with other node and tries to find a route then it broadcasts route request (RREQ) message to its entire neighboring node. The RREQ propagates with network and node which knows the route of destination. The destination sends a Route Reply (RREP) message with same path from which route request has arrived.

AODV need to keep track of following fields for each routing entry:

- Destination IP address

- Destination sequence number.
- Hop count-> Number of hops.

- Lifetime -> Time for which route is alive.

- Next hop -> Neighbor hop

- Active neighbor list ->Neighbor node that are actively participating in route.

- Request buffer ->It make ensure that a request is only processed once.

\subsubsection{AODV route discovery process}

When a node does not have a route for the destination or if route is previously expired. After broadcasting a RREQ, the node waits for RREP. and if reply is not received with in certain time interval the node may rebroadcast the RREQ. RREP is generated and unicasted backward to requesting node. This is a route discovery process of on demand protocol.

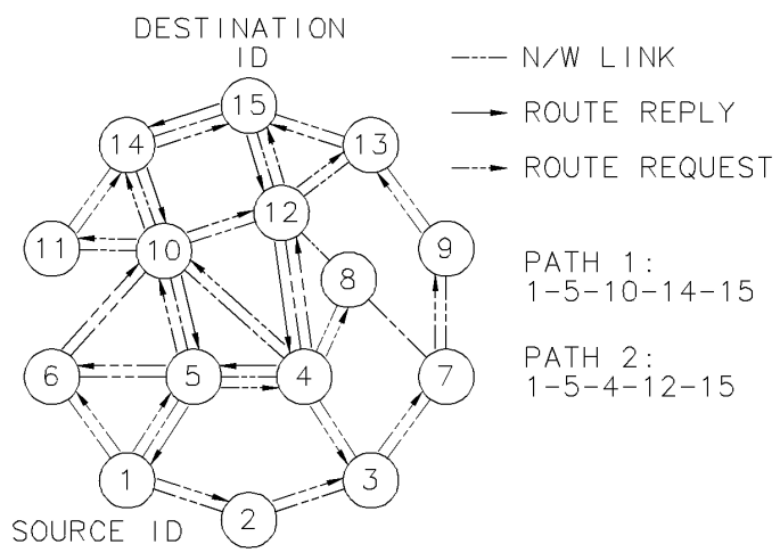

Figure 3: Route discovery in AODV

\subsubsection{AODV route maintenance}

When a route is no longer valid, it will remove from the routing entries and send a link failure message to all nodes, which are active in route. For, this purpose AODV maintain an active neighbor list.AODV does not repair a broken path. When a source node knows about path break or failure, it reestablishes the route to destination.

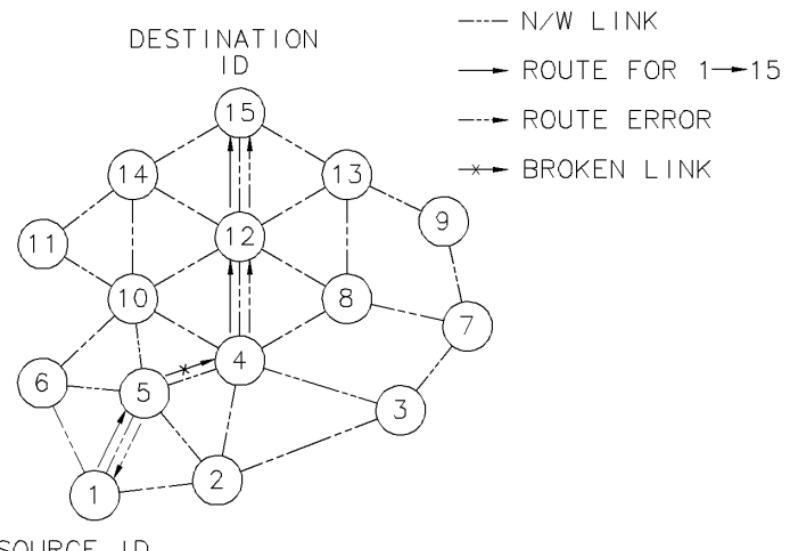

Figure 4: Route maintenance in AODV 


\section{International Journal of Science and Research (IJSR) \\ ISSN (Online): 2319-7064}

Index Copernicus Value (2015): 78.96 | Impact Factor (2015): 6.391

Comparison of Table driven and On demand routing protocol is shown in below table

\begin{tabular}{|c|c|c|}
\hline $\begin{array}{c}\text { S. } \\
\text { No. }\end{array}$ & $\begin{array}{c}\text { Table-Driven } \\
\text { (Proactive) }\end{array}$ & $\begin{array}{c}\text { On-Demand } \\
\text { (Reactive) }\end{array}$ \\
\hline 1 & $\begin{array}{c}\text { Attempt to keep consistent, up-to } \\
\text { data from every node to every } \\
\text { other node in network. }\end{array}$ & $\begin{array}{c}\text { A route is made only when it } \\
\text { is required. }\end{array}$ \\
\hline 2 & $\begin{array}{c}\text { Constant traversing of routing } \\
\text { information periodically even } \\
\text { when topology change does not } \\
\text { occur. }\end{array}$ & $\begin{array}{c}\text { No cyclic updates. Control } \\
\text { information is not traversed } \\
\text { unless topology is changed. }\end{array}$ \\
\hline 3 & $\begin{array}{c}\text { Incurs heavy traffic and power } \\
\text { consumption, which is generally } \\
\text { unusual in mobile computers. }\end{array}$ & $\begin{array}{c}\text { Does not incur heavy traffic } \\
\text { and power consumption } \\
\text { compared to table driven. }\end{array}$ \\
\hline 4 & $\begin{array}{c}\text { First packet latency is less when } \\
\text { correlated with on-demand. }\end{array}$ & $\begin{array}{c}\text { First packet latency is more } \\
\text { when correlated with table- } \\
\text { driven because route needs } \\
\text { to be built. }\end{array}$ \\
\hline 5 & $\begin{array}{c}\text { A route to each other node in Ad- } \\
\text { hoc network is always reachable. }\end{array}$ & Not Available. \\
\hline
\end{tabular}

\section{Network Simulator: NS-2}

The simulator, NS2 was developed by University of California at Berkeley and VINT. The NS2 was recently extended to give simulation support for Ad-hoc networks by Carnegie Mellon University. The NS-2 simulator provides many options that make it appropriate for our simulations.

A network condition for Ad-hoc networks.

- Wireless route modules (e.g. 802.11)

- Routing along numerous ways.

- Mobile hosts for Wi-Fi cellular networks.

NS-2 is an object oriented simulator written in OTCL and $\mathrm{C}++$. The simulator supports a class hierarchy in $\mathrm{C}++$ and an matching class hierarchy among OTCL interpreter. There is correspondence between interpreted hierarchies and one within the compile hierarchy. Two completely different programming languages is used because OTCL is appropriate for the programs and configurations that demand frequent and quick modification and $\mathrm{C}++$ is appropriate for the programs that have high demand in speed.

NS2 provide support for TCP and routing over wired and wireless network [14]. Once NS2 is download and installed, it contains the $\mathrm{C}++$ files for several different wired and wireless protocols from all layers in its repository. To implement a particular simulation, we write a TCL file to select which protocols we want to use from this NS2 collection. The TCL file is implemented on a scenario file. Scenarios are simulated environments generated by NS2. When user supplies information like the Number of Nodes, the size or area, simulation time etc., scenario files get generated. These scenario files can be saved and different protocols modifications can be run on them. This way, changes in the code can be measured and studied. We decide to choose NS-2 as network simulator for our thesis because:- NS-2.35 is open source freely available software. It can be facilely downloaded and installed.

- Programming language $\mathrm{C}++$ is compatible.

\section{Simulation Scenario}

For simulation, random may point model is used as a mobility model. The traffic source is CBR and data packet size is 40 bytes. The source destination pair is spread over network in rectangular field of 500x500. During the simulation each node starts its journey from random spot to a random chosen destination. Once a destination is reached, node takes a pause in seconds and after pause time, each node change its position with speed of $20 \mathrm{~m} / \mathrm{s}$. This process repeats throughout simulation, causing continuous changes in topology of network. To estimate the performance of protocols, simulation was conducted in which we have varied the number of nodes, mobility and pause time.

\begin{tabular}{|c|c|}
\hline Parameter & Value \\
\hline Simulator & NS2.35 \\
\hline MAC Type & Mac/802.11 \\
\hline Simulation time & 150 seconds \\
\hline Channel Type & Wireless \\
\hline Routing protocol & AODV/DSDV \\
\hline Antenna & Omni Antenna \\
\hline Simulation area & $500 \mathrm{mx} 500 \mathrm{~m}$ \\
\hline Traffic type & CBR \\
\hline Interface queue length & 50 \\
\hline Interface queue type & Priority queue \\
\hline Number of nodes & $20,40,60$ \\
\hline Pause time & $0,10,20,40,100$ seconds \\
\hline Mobility model & Random way point mobility \\
\hline Number of & $5,10,15,20$ \\
Connections/Traffic/CBR Load & \\
\hline
\end{tabular}

\section{Performance Results}

\section{Comparison of AODV and DSDV:}

\begin{tabular}{|c|c|c|}
\hline Number of Nodes & AODV (PDR in \%) & DSDV (PDR in \%) \\
\hline 10 & 99.59 & 99.92 \\
\hline 20 & 99.49 & 99.68 \\
\hline 40 & 99.58 & 99.30 \\
\hline 60 & 99.34 & 99.50 \\
\hline
\end{tabular}

\begin{tabular}{|c|c|c|}
\hline $\begin{array}{c}\text { Number of } \\
\text { Nodes }\end{array}$ & $\begin{array}{c}\text { AODV(Normalized } \\
\text { Routing Load })\end{array}$ & $\begin{array}{c}\text { DSDV(Normalized } \\
\text { Routing Load })\end{array}$ \\
\hline 10 & 1.66 & 1.00 \\
\hline 20 & 1.33 & 1.00 \\
\hline 40 & 1.00 & 1.04 \\
\hline 60 & 1.27 & 1.09 \\
\hline
\end{tabular}

\begin{tabular}{|c|c|c|}
\hline $\begin{array}{c}\text { Number of } \\
\text { Nodes }\end{array}$ & $\begin{array}{c}\text { AODV(Normalized } \\
\text { Routing Load })\end{array}$ & $\begin{array}{c}\text { DSDV(Normalized } \\
\text { Routing Load })\end{array}$ \\
\hline 10 & 1.66 & 1.00 \\
\hline 20 & 1.33 & 1.00 \\
\hline 40 & 1.00 & 1.04 \\
\hline 60 & 1.27 & 1.09 \\
\hline
\end{tabular}

5.1 Performance based on Number of Send, received and route packets with pause time and CBR load: 
International Journal of Science and Research (IJSR)

ISSN (Online): 2319-7064

Index Copernicus Value (2015): 78.96 | Impact Factor (2015): 6.391
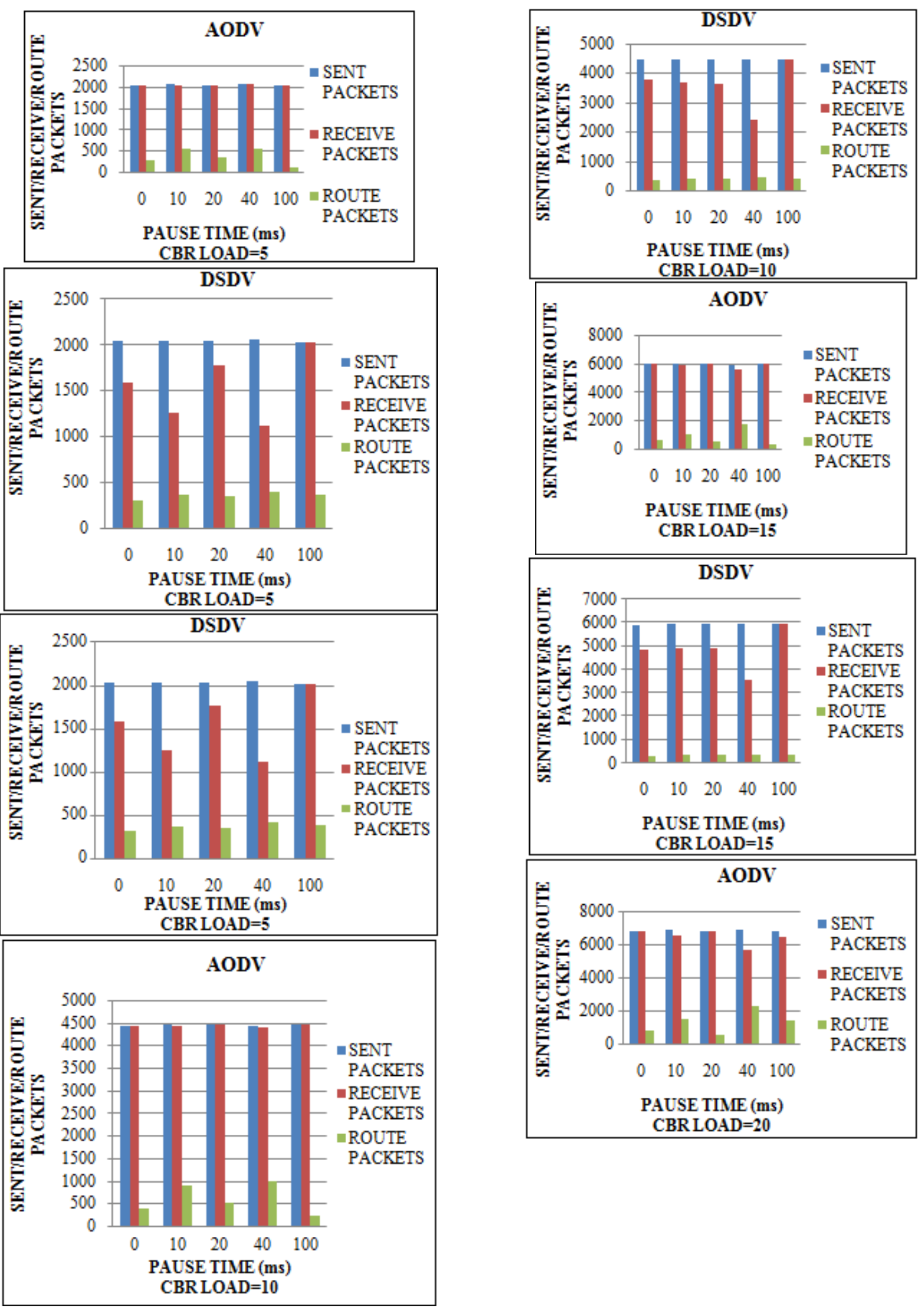

Volume 6 Issue 7, July 2017 www.ijsr.net 


\section{International Journal of Science and Research (IJSR) \\ ISSN (Online): 2319-7064}

Index Copernicus Value (2015): 78.96 | Impact Factor (2015): 6.391

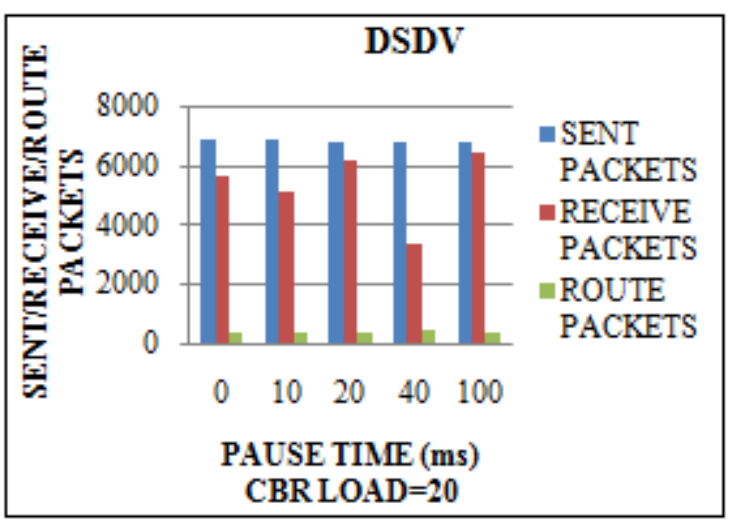

\section{Conclusion}

\subsection{Conclusion}

We have evaluated performance of MANET routing protocols based on different performance metrics under various network circumstances like increasing number of nodes, increasing pause time and number of connections. The performance of one proactive (DSDV) and one reactive (AODV) routing protocol is evaluated.

Results shows DSDV have less end to end delay because DSDV updates routing information on each node regularly. Average end to end delay of AODV is higher than DSDV. When number of nodes increases, AODV delivers a greater percentage of data packets, Packet delivery ratio of DSDV is batter as compared to AODV and Jitter of AODV is high as compared to DSDV. Under high mobility (pause time) AODV has better performance than DSDV. When Traffic (CBR Load) increases means increases number of connections than both AODV and DSDV has almost same performance.

\subsection{Applications}

Battlefields consist of humans as well as large number of communication equipments like wireless radios and many computational devices need to communicate amongst themselves to enhance the effectiveness in battles. Most of defence related networks are infrastructure-less as they builds on the basis of need in battlefields therefore such networks will be a perfect example of Mobile Ad-hoc network where the nodes are moving, some nodes are destroyed and hence nodes coordinate with each other to maintain the network. Such network is ad-hoc in nature. In these kind of networks, Reactive routing protocol AODV can be used for terminals as the overhead of this routing protocol are less, the routing overhead is an important factor in these kind of terminals used in battlefields because they are battery driven and hence they need to save power for longer times.

\subsection{Future Scope}

Another application of these protocols can be VANET (Vehicular Ad hoc networks) where vehicles act as moving nodes. In these kinds of networks the nodes mostly share their location information amongst themselves and hence form a network. Though the performance of these protocols is good for MANET but we can customize the protocol further as per application. For example in case of VANET the mobility patterns of vehicles in a convoy is not completely random as most of the vehicles in VANET move in a particular direction. The speed of vehicles are also within a known range therefore simulation studies can be carried out in future for such environment and the protocols can be further optimized for achieving maximum throughput whereas in such cases routing overhead is not that critical factor. Therefore in future I plan to customize on of such protocols for VANET characteristics

\section{References}

[1] Shiva ram murthy, B.S. Manoj, "Adhoc wireless networks: Architectures and protocols", ISBNo-13147023-X-pearson education, 2014.

[2] Jiang, H and J.J. Garacia-Luna-Acenes,"Performance comparison of three routing protocols for Ad-hoc networks", proceeding of IEEE ICCCN 2013, pp:547554

[3] Shell programming http://www.linuxfocus.org/english/september2013/arti cle216.sht

[4] Elizabeth M Royer, C-K Toh "A review of current routing protocols for Ad-hoc cellular wireless networks", 168-175, 2014, ISSN 1682-6027, IEEE, PP 46-55, 2014.

[5] P. Mani and D.W. Petr, "Development and performance characterization of AODV routing for CBR and TCP traffic in proc. Wireless telecommunication symposium, May, 2014 PP. 44-51, 14-15.

[6] Charles E. Perkins, Pravin Bhagawat, "Highly dynamic destination-Sequenced distance vector routing (DSDV) for mobile computers, "Proceedings of the conference on communication architectures, protocols and applications, pages 234-244, London, England, August 2014.

[7] M. Marina and S. Das, "On-demand multipath distance vector routing in Ad-hoc networks", in proceedings of international conference for network protocols (ICNP), Riverside, Nov 2015.

[8] Boukerche, A. (2015, April) Performance comparison and Analysis of routing algorithms. IEEE International conference on performance, computing and communication, PP. 171-178.

[9] NS 2.35 Simulator for beginners by Eitan Altman and Tania Jimenez.

[10] C. Perkins, E. Royer, "Ad-hoc On-demand distance vector routing", Proceedings of second IEEE workshop on mobile computer system and applications, 2013, PP 90-100.

[11] K. Aditya Reddy, T Sri Harsha, "An efficient DSDV routing protocol for Wireless Mobile Ad-hoc networks and its performance comparison", IEEE-2014.

[12] Marc Gries Tutorial for Network Simulator "ns" http://www.isi.edu/nsnam/ns/tutorial/index.html

[13] David A. Maltz, Josh Broch, JorjetaJetehena and David B. Johnson, "The effect of on-demand behavior in routing protocol for multichip wireless Ad-doc networks", IEEE journal on selected areas in

\section{Volume 6 Issue 7, July 2017




\section{International Journal of Science and Research (IJSR) \\ ISSN (Online): 2319-7064}

Index Copernicus Value (2015): 78.96 | Impact Factor (2015): 6.391

communication special issue on mobile and wireless networks, pages 1439-1453, August 2013.

[14] Rushikesh Dhananjay Imade, " Performance comparison of AODV and DSDV routing protocols in wireless Ad-hoc networks", International journal of Technical Research and Application, June-2015.

[15] "Comparative Analysis and Implementation of DSDV and AODV routing protocol for MANET", Snehal Govardhan, Akansha Choubey, International journal of Computer techniques June-2015.

[16] "mohittahiliani.blogspot.com" blog for NS2.

[17] "Performance Evaluation of AODV and DSDV using NS-3" Amandeep Kaur, Anuj kumar gupta, International journal of Innovations in Engineering and Technology (IJIET) FEB-2016. 